\title{
The Limits of Conceptual Analysis in Aesthetics
}

\author{
Karlheinz lüdeking
}

\begin{abstract}
In order to understand why analytic aesthetics has lost a lot of its former intellectual stature it is necessary to combine historical reconstruction with systematic consideration. In the middle of the twentieth century analytic philosophers came to the conclusion that essentialist theories of the "nature" of art are no longer tenable. As a consequence they felt compelled to move to the meta-level of conceptual analysis. Then they tried to show how a purely classificatory concept of art is used. The presupposition, however, that there actually is such a concept can only appear plausible at first sight. Upon closer inspection it turns out to be utterly misguided.
\end{abstract}

KEYWORDS Analytic aesthetics, theories of art, conceptual analysis

Analytic aesthetics has, for quite some time, lost a lot of its original fascination. Art-lovers, especially aficionados of contemporary art, are nowadays usually drawn to books by Deleuze, Agamben and Rancière whereas others, especially those who prefer the art of the old masters, often abstain from reading any philosophical treatises at all in order to occupy themselves with studies in the history of art instead. Thus, if there is still an interest in aesthetics it is most likely focussed on theories conceived in the wake of "continental" thinkers like Bergson, Benjamin and even Schiller. Analytic aesthetics, by contrast, is widely considered to be pettifogging, boring and irrelevant.

Such a low esteem, I think, has not emerged without reasons and, therefore, it would be foolish for analytic philosophers to deny that there are any shortcomings in analytic aesthetics. On the other hand such shortcomings need not necessarily be ascribed to the use of the methods of analytic philosophy as such. No one can seriously claim that an analytic approach to the problems of aesthetics must be misguided right from the start. It is, on the contrary, quite obvious that the methods of analytic philosophy proved to be very powerful in revealing the many weaknesses of traditional theories of art. Therefore, it certainly was a very beneficial achievement when the spirit of careful analytic clarification finally reached even the remote area of aesthetics in the middle of the last century. It swept away a lot of murky speculation and barely concealed propaganda. Moreover, it gave rise to the long overdue insight that in aesthetics, just as in all other areas of philosophy, it is no longer 
possible to fix all of our attention directly on the phenomena themselves and that we must, instead, first get clear about the meaning and the use of the concepts through which we refer to these phenomena.

At the same time, however, the pioneers of analytic aesthetics developed a certain fixed idea of how the analysis of the relevant concepts - and especially of the concept of art - must proceed, and it is this fixed idea, I want to show, that is responsible for most of the unsatisfactory results of analytic aesthetics. In this paper I can only try to prove this, though, with regard to the concept of art itself. Here the basic problem is that most analytic philosophers treated this concept - the concept of art - not as a value-concept but as an essentially classificatory concept whose primary function is to delineate a certain empirically definable class of artefacts. For reasons I will try to elucidate, this attempt seemed to be the only possible alternative to traditional theories that had become untrustworthy because they pretended to reveal the "real essence" of art but in effect were only more or less disguised attempts dogmatically to maintain a necessarily one-sided normative ideal of art.

The conviction that the concept of art must be understood as a nonnormative concept thus arose in opposition to the normativity of traditional theories. It has, right from the start, shaped the enterprise of conceptual analysis in aesthetics and has dominated most of the various attempts to clarify the meaning or use of the concept of art. It is a fundamental starting point for nearly all the initial proponents of analytic aesthetics - notably Morris Weitz, William Kennick and George Dickie. It does not, however, play an important role in the writings of philosophers like Nelson Goodman or Arthur Danto, who were not so much interested in the semantics of the concept of art than in art itself as a semantic phenomenon. It is no accident, then, that the work of these two philosophers is still widely read and discussed today whereas the others are more or less forgotten.

Nevertheless, I think, it can be helpful to elucidate the reasons for the failure of their efforts. In order to understand why the conceptual approach to the philosophy of art was incapable of developing a convincing alternative to traditional theories it is advisable to concentrate on the paradigmatic case of Morris Weitz who was one of the first and one of the most influential advocates of linguistic inquiries in aesthetics. His work is of special interest also because he is a renegade: He had to perform, in his own intellectual development, the very turn against the traditional way of thinking about art that became the hallmark of the whole school of which he was a leading figure. 
The "traditional" approach to the philosophy of art, against which the analytic rebels had to take their stand, is, first of all, closely related to our ordinary and spontaneous thinking about the subject which would suggest that there must be some specific peculiarities that distinguish artworks from other things. This is by no means an absurd idea: After all, it cannot be denied that, in practice, we constantly make distinctions between artworks and other things, and that we employ certain criteria in doing so. Thus it must initially seem only reasonable to assume that there are specific properties by which we can distinguish artworks from everything else. In philosophy, this highly intuitive idea inspires the "essentialist" program of inquiring into the "real essence" or "nature" of art which can be stated in a "real definition." It is, thus, no surprise that Weitz himself initially considered it self-evident that the essentialist strategy of looking for the defining properties of art is the only possible way of doing philosophical aesthetics. In his 1950 book Philosophy of the Arts, he still asserts, without any trace of doubt, that his task is to search for "the definition of the nature of art," and he actually proposes such a definition, claiming that the essential property of artworks is the complex unity of their sensuous and expressive features.

Now it is very instructive to examine the reasons that led Weitz to the conclusion that a traditional theory of art (of which he had produced his own specimen) is ultimately untenable. We cannot, however, get clear about this matter if we take at face value the reasons Weitz himself gives in his seminal paper on "The Role of Theory in Aesthetics" (published in The Journal of Aesthetics and Art Criticism in 1956 and repeatedly reprinted later). This paper would suggest that his most important reason for dismissing traditional theories was his recognition that they had been based on semantic confusions. He writes that it is the "logic of the concept" that prevents us from laying down necessary and sufficient conditions for the concept of art and thereby "to close" this concept, as he likes to say. His real reason, however, is a purely pragmatic one. This is openly admitted by Weitz himself in the following passage: "We can, of course, choose to close the concept. But to do this with 'art' ... is ludicrous since it forecloses on the very conditions of creativity in the arts."

An essentialist definition of the concept of art is, thus, in no way "logically" (or semantically) impossible, it is merely "ludicrous." It has to be rejected only because of the practical consequences that, in his opinion, follow from it. There is one consequence in particular that Weitz is afraid of: Since a definition of the concept of art always has to tie its use, once and for all, to one particular condition or set of conditions, it would nec- 
essarily have the effect of excluding novel works of art exhibiting qualities that nobody has ever dreamt of before. A "closed" concept could, thus, simply not remain faithful to the revolutionary development of modern art as it actually takes place.

In order to confirm this point I beg the reader to imagine Weitz being invited to the opening of the permanent exhibition of the Arensberg Collection (including a number of works by Marcel Duchamp) at the Philadelphia Museum of Art in 1954. There he would, for instance, have been confronted with a work from 1916 entitled Peigne en fer that consists of a small metal comb with an enigmatic French inscription: 3 ou 4 gouttes de hauteur n'ont rien a faire avec la sauvagerie. This work, as Weitz would probably have admitted, does certainly not strike its viewers by means of its "sensuous and expressive features" and their "organic composition into a unified whole" as it should do if the theory of art that Weitz had formulated only four years earlier was right. Nevertheless it was, by one of America's most prestigious museums, exhibited as an artwork of undisputed significance. What could Weitz then, on this occasion, have done with his definition that he had taken such pains to elaborate? I think he would have had to face three equally unpalatable alternatives.

First, he could have admitted that he was simply wrong, since, obviously, there are works of art of generally acknowledged importance that do not display the quality he had taken to be their defining property. Weitz could thus have dropped his definition - though without realistic hope of finding a better one that would have avoided this fate.

Secondly, he could have tried to expand his definition so that it eventually can include cases (like the one at hand) that it does not immediately fit. Pursuing this strategy, however, he would have progressively emptied his definition of all content. Of course, nothing would have prevented Weitz from insisting that even this unspectacular work by Duchamp that consists of an ordinary metal comb displays a certain organic unity of sensuous and expressive features. But that would have been a rather shallow move which does not really save his definition, because, even if that obscure assertion would have been granted, it would nonetheless have been doubtful whether it is actually this peculiar quality that makes Duchamp's comb a work of art.

In order to uphold his definition Weitz would thus have had to choose the third and last possibility: He would have had to claim that the strange work of Duchamp really does not fit his definition and that it, therefore, simply cannot be a work of art at all.

Initially someone committed to a certain definition of the "nature" of 


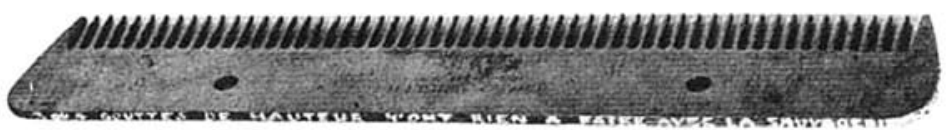

Marcel Duchamp: Peigne en fer (1916). The Arensberg Collection, The Philadelphia Museum of Art. 
art will most likely choose the last alternative since it does not imply concessions on the part of his theory. This alternative, however, is not only the most probable, but also the most pernicious. If a philosopher just drops his definition of art or expands it beyond recognition, he does not cause any harm, except perhaps to his own pride and reputation. But a stubborn insistence that certain unconventional artworks cannot be art at all may be more deleterious: It may have the effect of degrading and discouraging artists producing such vanguard products and, more seriously, it may bar all of us from important and substantial experiences that these novel works might have to offer.

It is no surprise, then, that Weitz is primarily worried about this last possibility. He is very much aware of the potentially restrictive effects of a definition of the concept of art. And he is moved to criticise traditional theories because he is convinced that each of these theories is in constant danger of degenerating into a normative dogma which engenders an arbitrary demarcation between art and non-art. This fate can, of course, be avoided if the criteria proposed by the theory are so weak or so vague that they cannot determine a clear-cut distinction anyway. But if the theory wants to state criteria that allow for such a distinction, it will inevitably have to pin down boundaries that in reality are not fixed. After all, it is an undeniable fact that the class of artworks is continuously able to include novel works that could not have been included before. Therefore, any workable and effective definition has the unpleasant effect that certain members of the class of artworks have to be excluded - although they have, by common consent, already gained a place in that class of things.

If a theory, however, leads to such a deviation from the generally accepted distinction between art and non-art, it is clear that it does not reveal the criteria on which the actual classification of artworks is based. It does not describe the use of the concept of art as it actually takes place, it can only prescribe a certain use that is not generally accepted. Accordingly, the criteria it states can only have a normative function: They lead to an arbitrary selection of things that are allowed to enter the privileged precincts of art. By adopting these criteria one is thus committed to a limited and necessarily one-sided view of art that is not (or no longer) shared by all the others who obviously apply the concept of art on the basis of different criteria in order to make different distinctions.

Weitz was thus - and I think, quite correctly - led to the conclusion that the attempt of traditional philosophers to tie the concept of art to certain fixed conditions will always result in an arbitrarily restricted use of the concept that is in contradiction to the generally accepted classification of 
artworks in our society. In his opinion, however, a philosophy of art must by all means avoid this effect. Weitz was convinced that the aesthetician has no right to set up a normative ideal of art and to force it upon the public, because, as the history of aesthetics shows, this can only lead to theories that will, for ever, remain contested and precarious.

But how can a theory of art avoid sliding into such questionable normative statements? For Weitz it was clear that it does not ensure the neutrality of the theory if only it is elaborated in compliance with strictly empiricist standards. Even the most scrupulous search for peculiar properties of art based on the most careful and unbiased investigation will suffer the shameful fate of being - unintentionally - transformed into a restrictive norm at a certain point of time, namely when novel works of art are created that simply could not have been taken into account before. Thus, if even utmost sincerity and willingness to adapt one's theory to the facts cannot save one from committing the sin of normativity, the only thing left is to switch to the meta-level of conceptual inquiry. And this conceptual inquiry, in turn, must itself of course be strictly neutral, because it was motivated precisely by the hope of avoiding any unjustified normative implications.

Thus Weitz came to the conclusion that the only alternative to traditional theories is a completely non-normative approach located on the meta-level of conceptual inquiry. And this is actually still a plausible conviction. The fateful thing was that Weitz, right from the start, conflated a non-normative theory of the concept of art with a theory of a non-normative concept of art.

I will now advance some conjectures about the motives that may have led Weitz to this remarkable conflation, which was later mindlessly taken over by many other philosophers so that it eventually became an unquestioned dogma of analytic aesthetics.

Most important in this respect is the fact that Weitz was primarily concerned with the question how the extension of the concept of art is determined. This is quite understandable insofar as the basic problem for traditional theories was, indeed, that they were never able to get clear about the limits of the class of things they were talking about. Their necessarily generalising propositions about common properties of all artworks failed again and again, because the class of things these generalisations were meant to cover was itself in constant flux. The basic problem, therefore, appeared to be the problem of determining how the classification of artworks takes place, because unless this problem is solved nothing reliable can be said about the things that belong to this class. 
Now, the fundamental observation of Weitz must have been that, in our society, there simply exists a certain class of objects that are actually treated as artworks, independently of the opinions or attitudes of any particular individual in this society. Everyone must then also designate these objects as artworks, no matter how their value may be appraised from any individual's point of view. Thus, the question whether a given thing is actually a member in the class of artworks appears to be a simple matter of fact which is completely independent from any normative assessment. Therefore, Weitz concluded, the task to pick out this class of things can only be accomplished by a purely empirical concept of art that is not based upon any normative standard. This led him to believe that there must be a purely descriptive or classificatory concept of art.

Other analytic philosophers shared this belief and so a number of different accounts of a purely descriptive concept of art were worked out. Basically there are four plausible variants of such accounts. Two of them regard the concept of art as a concept of ordinary language. On the one hand, we have here the theory of Morris Weitz himself, according to which the concept of art is a "family-resemblance-concept" with a flexible set of criteria. On the other hand, there is the theory of William Kennick who suggests that the use of the concept is analogous to that of perceptual concepts so that there is no need to make use of any criteria at all. The remaining two variants see the concept of art as a theoretical concept which is used on the basis of complex criteria - criteria that may well even be normative ones. These theories, however, assume that the meaning of the concept is independent of the criteria that determine its application to specific cases. Here we first have the theory of George Dickie: The concept of art designates objects with a certain status, so that the criteria for acquiring this status are no longer relevant for the semantic content of the concept. And secondly we have the "rigid-designator-theory" as advocated, for instance, by James Carney. This theory also eliminates any semantic relevance of the (changing) criteria that different speakers use to discover what belongs to the extension of the concept.

This is not the place to demonstrate at length why none of these theories was able to give an informative account of the actual use of the concept of art. ${ }^{2}$ I only want to point out that it is a remarkable common feature of all these theories that they have the effect of detaching the meaning of the concept of art from any criteria strong enough to entail a genuine decision about any given cases. In order to avoid normative restrictions, each of these theories has to describe the use of the concept of art in a way that can no longer really tell us where the concept does or 
does not apply. Such information should, however, be expected from a theory that claims to describe the use of a purely classificatory concept of art through which the empirical class of artworks is supposedly delineated. These theories can therefore not even live up to their own claims.

This is no wonder, because what is at stake here is simply not ordinary classification. The membership in the class of artworks is not a plain matter of fact; rather, it depends entirely upon decisions about artistically valuable qualities of the objects in question. And therefore the question whether or not to apply the concept of art in these cases cannot simply be settled by appeal to certain generally accepted criteria - as it would be the case with a purely descriptive or classificatory concept. The concept of art is primarily used as a value-concept. For it is a characteristic peculiarity of value-concepts that their application to given cases is never determined by their generally accepted (linguistic) meaning or the conditions of their (linguistically correct) use.

I would like to demonstrate this by means of a simple example: Everyone who is able to read this essay knows the meaning of the word "good" very well, but this knowledge alone does not suffice to determine whether this essay may or may not be called good. One can only answer this question if one chooses (or has already chosen) criteria that constitute a normative conception of what is to count as a good philosophical paper. And since there can be different and contradictory opinions about this matter the criteria required for the application of "good" in such a case, obviously, cannot be determined by the generally accepted rules of language.

In a similar way, someone - say any one of the above mentioned authors - who clearly knows (and is even an expert of) the meaning and use of the term "work of art," is not, through this knowledge alone, enabled to determine, for instance, whether a simple metal comb with a French inscription may or may not be called a work of art. In order to decide this question it is necessary to make use of criteria that constitute a normative conception of what is to count as a work of art. And again there can be different and contradictory opinions about the matter. According to the criteria of the early ("traditional") Weitz the concept of art cannot apply, but it certainly may apply if we employ other criteria (like self-reflexivity or meaningfulness). And the choice of these criteria is again not determined by the generally accepted meaning of the concept of art.

In a certain sense, however, the question whether the concept of art may be applied in such a case is indeed a question that is independent of any normative assessment. After all, it really is a plain matter of fact whether a given object is a member of the class of things actually treated 
as artworks in our society or not. Accordingly, there must also be a purely descriptive use of the concept of art which simply states the membership in this class. This is true. But, as the theory of Dickie reveals most clearly, this use of the concept can only be a derivative use that completely depends upon the fact that the membership in this class is already bestowed on the object in question. This membership itself, however, is only awarded to objects that satisfy certain normative standards.

Now it is possible to see the dilemma that is manifested in the unfortunate antagonism that developed between traditional philosophers of art and their analytic adversaries.

Traditional philosophers, committed to the essentialist strategy, tried to tie the application of the concept of art to one particular criterion or a set of such criteria. And in a way they were quite justified in doing so, since the application of the concept to any specific case must indeed be based upon explicit criteria that enable a clear-cut decision about whether something is art or not. Traditional theories, however, never realised that such criteria can only be based on normative conceptions and that they can therefore not be presented as criteria that are simply determined by a given and unchangeable "nature" of art which is already out there waiting to be discovered.

Analytic philosophers realised this, and they pointed out that the membership in the class of artworks is not determined by some eternal essence shared by the members of this class, but by distinctions made by society. But since these distinctions may change over time, they can obviously not be based upon one criterion that is fixed once and for all. Moreover, the fact that, at a given time, a certain class of things is classified as art does not prevent us from taking divergent evaluative attitudes to the members of this class. This shows that someone who uses the concept of art in accordance with the generally accepted rules of its use is not thereby forced to accept one particular normative criterion for its application.

As we have seen, however, the various attempts of analytic philosophers to show how the concept of art may be used without any commitment to normative criteria had so unsatisfactory results that they finally lost all credibility. Certainly, these philosophers were quite right in saying that the concept of art must have a generally accepted meaning compatible with different standards of value. But they were wrong in their conviction that the generally accepted meaning of the concept - which has to be employed by anyone, whatever his normative attitude in respect to different artworks may be - will by itself settle its application to particular cases. As 
with "good," the ascription of the concept of art to a given case is not possible without choosing normative criteria relevant to this case.

These criteria may change from case to case and from time to time, and different persons may use different criteria for the same case. Therefore, the generally accepted meaning of the concept of art must indeed be independent from all these floating criteria. But this does not mean that we have to understand the actual use of this concept independently from these criteria. To the contrary, we have to realise that the concept of art could not even be used in one single case without the employment of one of these (divergent and changing) normative criteria.

But if the concept of art is basically a value-concept, how can we then explain the undeniable fact that there is a certain class of things that - no matter how we would judge their value - are, at a given time and in a certain society, generally accepted and designated as artworks? It is clear, after all that has been said, that the demarcation of this class of things cannot simply be the result of the uniform use of one and the same classificatory concept. In my view, rather, the class of artworks has to be understood as an unintended and unforeseeable overall result of all the divergent and conflicting applications of the concept of art by all the different speakers who all use different normative criteria. Thus, although each of the single ascriptions of the concept of art is based upon a normative distinction, the general outcome constitutes a simple empirical fact - the fact that a certain number of things are now actually accepted as the class of artworks.

The existence of an empirically delimitable class of artworks, therefore, does not mean that there must also be a corresponding concept which serves the function of a purely empirical delimitation of that class. Rather, the existence of this class has proved to be entirely compatible with the fact that each particular distinction between art and non-art requires the employment of a normative criterion. And if the class of artworks is delimited by the combined effect of the whole number of competing normative distinctions between art and non-art, then the idea that the concept of art has to be treated as a descriptive and classificatory concept must be considered a myth.

We can now appreciate why the results of a purely conceptual approach to aesthetics had to be rather disappointing. In order to learn about the distinction between art and non-art, we must explore not our concept, but our conceptions of art. Conceptual analysis will never yield much insight if it is concerned with value-concepts. Therefore, the attempt to do philosophy of art by inquiring into the generally accepted 
meaning of the concept of art is not very productive. The results are thin, because there is little to discover.

But does the failure of both traditional as well as analytic approaches to the problem of the definition of art in the end mean that there is nothing left to do for a philosophy of art? I do not think so. Of course, on the one hand it has become clear that it is an absurd ambition to reveal what art "really" is, because every theory about the "real nature" of art will sooner or later be unmasked as a normative dogma. On the other hand, it has proved to be equally absurd to turn to the rules of language in order to learn what art is. However, realising this, we are only released from constraints. Our understanding of art is no longer restricted by the strange fiction that art is a phenomenon whose peculiarities are determined independently of us - either by the nature of things or by the rules of language. Once we overcome this delusion, we gain the freedom to reflect upon the only aspect of art that is really important to us. We see that art cannot be understood as independent of the divergent ways in which we are able to conceive of its many merits.

What we have to do, then, is this: First we must clarify the normative conceptions of art that we have - more or less unconsciously - inherited and adopted, and then we have to consider whether we have good reasons to stick with them, or whether we should go beyond them towards something new. This sounds trivial and it is trivial. It is, thus, all the more surprising that such a banality could have been neglected for so long by an entire school of aesthetics. In practice, however, most persons interested in art have already done the only reasonable thing all along. Someone who is seriously interested in art simply cannot help to reflect upon his conception of art in light of its social and historical conditions. Probably some of the readers will feel that such a self-reflective approach to aesthetics is not really "philosophy" any more, but only art criticism. But, whatever it may be called, I am convinced that this is the only way to understand what art is - which, in the end, is also a way of understanding what we are ourselves.

\section{Notes}

1. Morris Weitz, "The Role of Theory in Aesthetics," The Journal of Aesthetics and Art Criticism 15 (September 1956): 32.

2. A detailed analysis of the four theories mentioned - and much more on the problems of analytic approaches to aesthetics in general - can be found in my book Analytische Philosophie der Kunst (Frankfurt: Athenäum, 1988; second, expanded edition Munich: Wilhelm Fink, 1998). 
